\title{
Account Based Ticketing: The Benefits and Drivers for Transit Operators
}

\author{
Khaled Zohdi Zamer \\ Al Fattan Currency House, 23rd Floor, DIFC, Dubai, United Arab Emirates \\ Email: Khaled.zamer@gmail.com
}

How to cite this paper: Zamer, K.Z. (2018) Account Based Ticketing: The Benefits and Drivers for Transit Operators. Journal of Transportation Technologies, 8, 331-342. https://doi.org/10.4236/jtts.2018.84018

Received: July 4, 2018

Accepted: October 26, 2018

Published: October 29, 2018

Copyright $\odot 2018$ by author and Scientific Research Publishing Inc. This work is licensed under the Creative Commons Attribution International License (CC BY 4.0).

http://creativecommons.org/licenses/by/4.0/

\begin{abstract}
This paper aims to explore the importance and efficiency of using open payment cards in transit applications as an alternative to current propitiatory cards. This data can be beneficial to transit planners, from regular operation of the transit system down to the long-term strategic planning of the network. This paper covers several aspects of open payment cards in the transit planning context. First, the methods of payments are presented: cash, debit/credit cards, proprietary cards, and mobile payments. Then the several cases where open payments on transit are beneficial. Also reported are open card payment research conducted around the globe. Finally, the most promising online survey is performed to measure the perspective of the rider on using account-based ticketing versus the traditionally closed loop scheme. Mobility and payments are foundations pillars for developing communities and advancing economy [1].
\end{abstract}

\section{Keywords}

Transit Payments, Open Payments, Integrated Payments Ecosystem, Account Based Ticketing

\section{Introduction}

Millions of people use public transportation everyday around the globe; efficient and interoperable fare collection is becoming more important today than they've been ever in the past. Instead of using cash or propitiatory card, the myriad payment options today allow mass transit authorities to potentially reduce operational costs and increase public transport convince by using the right blend of payment instruments. The payment options offered to customers can positively impact their choice for using public transportation services which in turn may have indirect benefits to the sustainability and economic growth. There is 
another side for using open payments in transit for understanding the payment patterns as it produces large amounts of data on spending behavior, route planning, and onboard transactions. There are other benefits to banks as well by upselling financial products co-branded with mass transportation authorities and geolocation offers based on specific usage. However, there is a downside for using this payment instrument mainly in revenue sharing, customer data privacy, transaction authorization, and ticket validation. The pros and cons of each payment option are discussed below.

\subsection{Methods of Payments Used in Transit}

There are different instruments used in the fare collection, ACI study (2016) indicated that cash at a physical location takes the top position among different other options [2].

\subsubsection{Cash}

Despite the availability of different instruments cash is still the king in many parts of the world, due to different factors being social or economic or simply just because! Many customers reported they pay at the counter when purchasing the travel tickets. Transportation authorities adopted different payment technologies to make travel more convenient and efficient, yet the social and economic drivers still impacting cash to dominate this area.

\subsubsection{Credit/Debit Cards}

Customers using cards to purchase tickets at the counter, this is an alternative to cash transactions. This method will reduce the overhead costs from cash handling; however, there is a downside to it by reducing the merchant processing fees, even if that was nominal. The total cost for acquiring transaction might end up eating the profits or reducing it. On the other hand, this method can provide an opportunity for understanding the buying behavior and spending patterns. When comparing cash versus card payments, cash transactions typically cost twice as much as non-cash payments in overhead [3].

\subsubsection{Proprietary Cards}

The fact of the matter is most transit agencies have developed their own proprietary fare payment system. The need for such systems emerged years ago when the payment options were limited and not many alternatives were available to customers. Despite the fact these automated fare collection systems are still running yet we cannot deny the fact that cost of operations increases by the day, technology getting obsolete and difficult to maintain which making it hard for the transit authorities to reduce the cost, generate new revenues and develop innovative services.

\subsubsection{Mobile Payments}

Apple Pay, Samsung Pay, AliPay and many others are expanding globally, and customers are adapting to this new trend quickly. Few attempts have been made 
on to introduce mobile as a payment instrument. However, the biggest hurdle was in trying to bridge the technology gap between old fare gates, NFC, and feature mobiles. This dilemma can be solved by using stickers and memory cards can be used while the full NFC ecosystem works through development. Singapore took the lead in this area and partnered with AliPay and DBS bank to accept mobile initiated payments for commuters.

\subsection{The Study Motivation}

This paper is an attempt to understand the impact and acceptance for open payments on transit for easy to use and innovative alternative for everyday public transportation need. There have been few papers in this domain to measure the rate of adoption and understand the impact on technology, revenues, and convenience. The customer survey showed two key findings:

1) Customers prefer to use one payment source for everyday use;

2) There is a preference to use mobile initiated transactions for transit payments.

Technology plays a major role in increasing efficiency in transport sector and that can be demonstrated across all dimensions and levels from customer information, asset management, electronic payments, faster inspection of goods, emergency and accident management, domestic and regional exchange of information, to interactions between administrations and service operators, drivers and passengers, or tracking of shipments [1]. This study focuses on one area, the role of using integrated electronic payments in transport industry.

\subsubsection{Why Do We Need to Consider a New Fare Payment System?}

Most of the transit agencies offer some type of fare collection system that is purpose-built solely for the transportation industry. In many cases, there are different service layers between the buses, metro, subway, and taxis with minimal usage for other purposes like in station purchases from convenience store. Over the years, agencies implemented new technologies to replace cash, tokens, swipe card however despite the enormous investments, these cards are only used for transportation agencies and very limited to in-station purchase. So eventually agencies only replaced the collection mechanism and didn't evolve the ecosystem to benefit from other services such as loyalty points, transaction interchange, agile service deployments, productizing their services or even understand the customer spending behavior beyond transportation services. These previous points are critical to develop smart city strategies and to overcome some of the key challenges in urban planning.

\subsubsection{How Is Closed Loop No Longer the Solution for All Fare Collection Issues?}

This is a common term used in payments system to restrict what goods and services can be purchased and from which merchant. Closed loop payments offered significant benefits to transit authorities due to the ease of use, internal payment processing which reduce the cost of operations, and ability to monopolize the 
payment instrument. However, these benefits are decreasing as customers started to demand and dictate new methods of payments and services on banks telecom operators and they already transforming the landscape of services offered by these high-tech sectors where users demand higher speed, mobility, cashless and social networking with their peers. These drivers will sooner or later come to the transit industry with the introduction of autonomous cars, public charging stations, flying cars and other related inventions which closed-loop payment system cannot fulfill directly and requires cumbersome technology investments if considered to integrate with service providers to complete the missing parts.

There are factors impacting the global economy and changing the service paradigms, an emerging trend for mobile, cashless economy initiatives, reduce the cost of operation and creating the stickiness factors to increase the number of returning customer. First data report [4] highlighted that Transport of London spends $£ 100$ million a year to maintain the stored-value Oyster card system, another example from Southwest US spends \$39 million; this amount of money can be invested in more profitable business lines by merely offloading the payment collection to open payment system rather than the traditional self-contained closed system. The processes associated with card life cycle and transaction processing are redundant and already streamlined in the DNA of banking industry, moreover, running a proprietary card program requires much higher spending and complex operations to perform the same set of processes which transit authorities cannot achieve the economy of scale that financial institutions can. The takeaway from this is no matter how hard the transit companies try to maintain high standards in running their closed-loop payment program. Still, they won't be able to reach the same level that banks are offering to their customers today, and if they were to offer similar service levels, the price would be very high. Below are few concerns why the closed loop payments represent a future challenge to transit authorities:

- Operational overheads: as technology evolve, most of the terminals and fare gates become obsolete, the maintenance cost, on the other hand, increase proportionally as the devices get older which requires investments in changing the gate barriers and terminals.

- Vendor control: with the propitiatory hardware and software, the chances of getting competitive pricing or open integrations get smaller due to the sole vendor control of the business which creates additional challenges on the commercial side as well make it difficult to replace on the long run.

- Resource overheads and operational excellence: to maintain a satisfactory level of customer convenience, an enormous number of resources must be ready to process the fare collection and support customers which could unnecessarily impact the information technology, logistics, and call center.

- Inconvenience: public transport riders must purchase and carry intermediate payment instrument for one special purpose instead of paying for a ride using payment medium existing in their wallets, such as debit, credit or pre- 
paid card that can also be used for different purposes.

- Potential revenue loss: revenues generated from direct marketing, co-branded cards, or indirect cost savings from technology, resources or vendor control can be a potential loss of revenue.

\section{The Case of Account Based Payments}

There are different trends emerging in the payments domain and cast its shadow on the transportation industry, the prudent transit authorities, will need to re-evaluate the fare collection strategies and investments to incorporate new payment methods into their future roadmap.

\subsection{Electronic Payments}

In recent years' electronic payments became standard in everyday life, from buying a pint of milk to paying the bills or even purchasing a Ferrari. Capgimini (2017) [5], estimated 433 billion noncash transactions globally in 2014-2015, with the growth of $11 \%$ from previous year and CAGR of $10.9 \%$ between 2015-2020, the developing countries will lead the rally with CAGR 19.6\% during the same period.

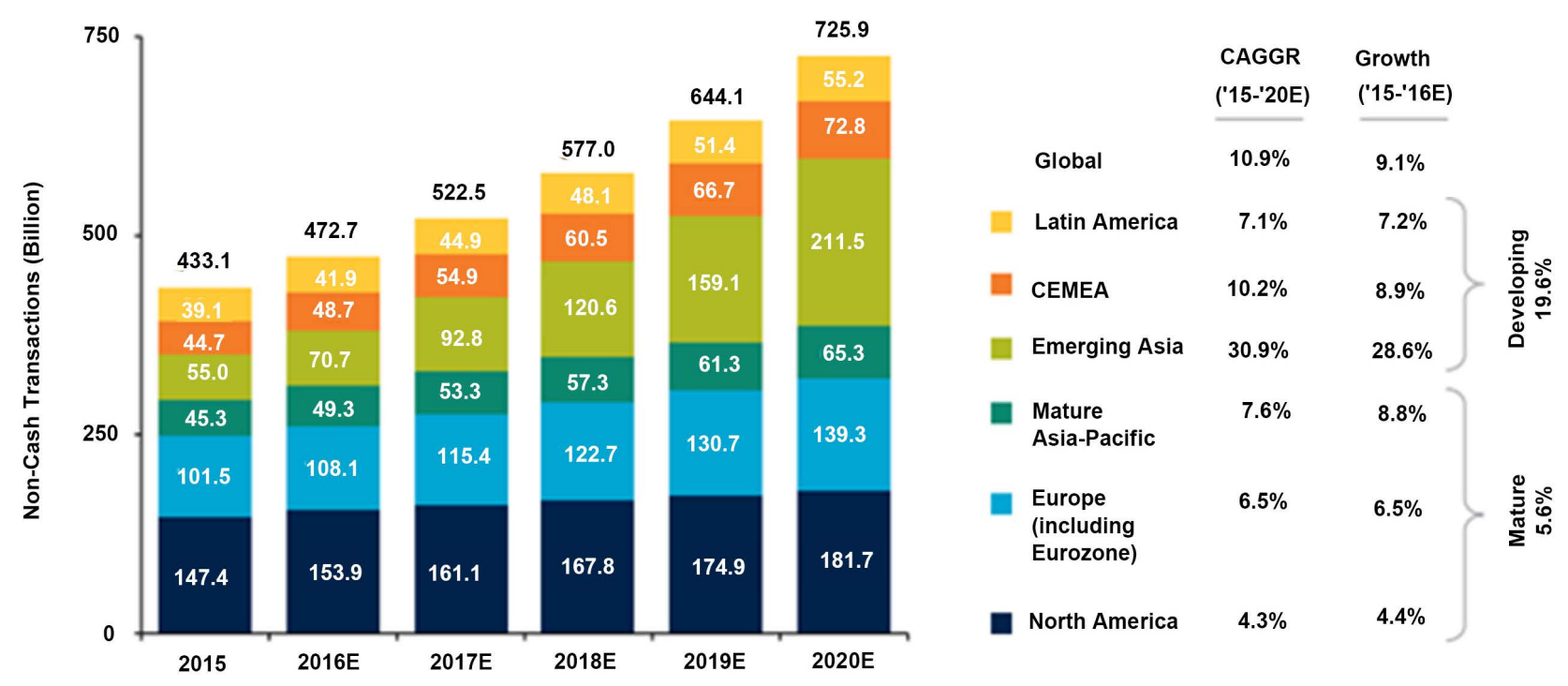

Source: Capgemini-World payment report, 2017.

\subsection{Prepaid Cards}

Prepaid cards gained momentum in recent years making it the fastest growing payment instrument, with the sheer value of fraudulent transactions online, and the emergence of gaming communities, prepaid cards are becoming a reality in everyday business. A study from First Data [6] highlighted that $9 \%$ of customers who are using the prepaid card would reload the card again for a second use, these reloadable cards are now used by employers for salary disbursement, by the government for social benefits and for the unbanked people who do not have 
a bank account. The prepaid cards are mostly used to conduct micropayments as well ride on a transit system.

\subsection{Open Loop Payment Systems}

The prepaid cards can be classified into two categories "Restricted" or unrestricted," while the restricted cards can provide a convenient solution for gift cards and loyalty scheme the open-loop cards are typically branded by the card schemes being Visa, MasterCard or American Express. The open loop cards can be used to conduct payments at almost any point of sale since the acquiring infrastructure is already built and in place for many years. The most significant advantage of open-loop cards that transit authorities don't have to support their own expensive payment system to process and settle payments themselves, but instead they can use already established and trusted networks.

\subsection{Contactless Payment Systems}

Many transit authorities implemented contactless systems to reduce the journey time at the gates as part of their proprietary fare collection system; this allowed consumers to conduct secure and easy payments, on the other hand, banks are now issuing credit and debit cards equipped with contactless features much more than before. The combination of customer adoption and getting used to the contactless transactions in transit service combined with the banks issuing RFID cards, transit service can benefit from this uptake in two factors, cost savings from reducing the overheads from processing propitiatory transactions as well getting more customers to use public transportation without having to buy special-purpose cards that might not be possible to use in everyday life.

\section{The Story of Bankcard Payments}

The bankcard standards are set by the common financial networks, Visa and MasterCard have been adopting these standards for long, and this standard is adopted by the member banks which make it an ideal vehicle to process high volume transactions, with the established settlement, reconciliation and dispute management process. Utilizing this standard comes with a cost of processing and interchange fees, however, still reducing the relative costs of operating closed loop payments mainly on the acceptance, card life cycle, and financial settlements. Many transit operators have a genuine interest in adopting the open bankcard standards for the aforementioned benefits and primarily for the improved customer experience. The adoption of bankcard payment standard the transit operators will take their operations out of the banking business and focus on the core operation of mass transportation and transit management without losing the customer experience. When transit operator become a merchant for card acquirers, they can negotiate a competitive deal for merchant management and prepaid program as well benefit from the co-branding and data sharing with banks. 


\subsection{The Benefits and Challenges}

Perhaps the most significant enticement of open bankcard is that transit authorities start reducing the cost of running extensive infrastructure operation used in issuing and managing the closed-loop payment scheme and offer convenient use of debit, credit and prepaid cards that are already in circulation which reflects positively on the rider's view on the service. The other immediate benefit is to reduce the number of interaction points, and offer a familiar experience. Customers on the other side would not need to worry about the need to have a special card for specific use and benefit from the geolocation offers from their banks. The banks will get to know where the customers are using their cards to offer discounts and special promotion based on that. As mentioned above, offering such experience brings benefits for all parties and reduces the cost of operation which reflects indirectly on carbon emissions, smart cities, and environmental factors. While that represents a utopian view, still the picture is not perfect. There are a few challenges associated with these benefits which are summarised hereafter.

\subsubsection{Transaction Security}

There might be some concerns when securing the payment transaction and communication between the card and the gate barrier or the POS device as well when the transaction is processed with the acquiring bank; the two key challenges are vulnerable payment technologies and phishing attacks. These challenges can be mitigated when working with trusted service providers and carrying annual audit checks to reduce the possibility of being exposed.

\subsubsection{Card Issuance}

This is a reducing concern as more banks are moving to contactless cards which will help customers to transact seamlessly. However, since the transit authorities are not involved in the card issuance, this risk is mitigated and shifted to the financial sector.

\subsubsection{Data Protection}

All transactions happening in the transit system needs to be protected and appropriately archived, it is worth mentioning that many transit authorities operate with a semi-government license and will follow the data protection guidelines. Nonetheless, it is highly recommended to adopt a data protection and security policies to eliminate the exposure.

\subsubsection{Settlement and Reconciliation}

Since transit authorities will process transactions through a 3rd party, transferring funds might take few days to reflect in the books. This could cause issues in disputed transactions or loss in revenue if the transaction was not captured correctly. In today's model, the balance is generally stored on the card itself and any financial transactions are calculated instantly, thus reducing the cost of processing and reduce the margin of errors. In the Account based ticketing, the 
bankcard doesn't have a stored value in order to get an accurate reading of the account balance, the transaction needs to be processed in less than $300 \mathrm{~ms}$, and mostly authorization needs to be instant to maintain similar experience to the propitiatory scheme. In many cases, transit authorities need to have special agreement with issuing banks to have a pre-authorization amount which allows the rider to buy journey tickets against that amount; this approach can reduce the cost of transaction processing even further where transit authorities will aggregate transactions and process it in bulk rather than sending individual requests to the acquiring partner.

\subsubsection{Interchange Fees}

In card payments, there is a fee associated with every transaction on a network. The term interchange is referred to a fee that a merchant's bank (Acquirer bank) pays a customer's bank (Issuing Bank) when the merchant accepts using card networks (Visa, MasterCard). In the context of the transportation industry, the merchant is the transit authority, and the customer is a rider. In the credit card payments, the issuing bank deducts the fees from the amount it pays the acquiring bank; the acquiring bank then deducts the interchange fee and the merchant discount fee before settling the payment with transit authority.

\subsection{Success Stories from around the World}

1) Department of Transport-London [7] launched the contactless payments, since then more than 10.7 million unique transactions been used. TfL partnered with $\mathrm{O} 2$ and Barclays bank to launch NFC payments in 2008, and the pilot showed more than $90 \%$ of the riders found the new service to meet or exceed the expectations [8]. The pilot program lasted for four months and involved 230 participants. 2018 new technologies became more common such as Samsung Pay app, and only 0.3 percent of the riders bought tickets from a machine at the station. TfL plans to go cashless by the end of the year [8].

2) Singapore land transport authority [9] launched a pilot with MasterCard on account based ticketing for public transport by allowing the use of contactless credit and debit cards for fare payments. The program simulates post-paid mobile phone subscriptions or utility bills; transactions will be processed and charged to the commuter in subsequent credit or debit card bills. Commuters will benefit from having an additional fare payment option, removing the need for top-up fare cards.

3) Queensland's public transport (Australia) [10] announced the commercial launch of account based ticketing service that will allow commuters to pay for the ride using debit or credit card. The program was launched in partnership with Commonwealth Bank.

4) Beijing China's public transport payments firm Yikatong [11] has released an app which enables Android smartphones to compensate for rides by tapping their smartphone instead of using their transport card last 2017. The upgrade fits very well with the habit of Chinese of using smartphones to pay for anything 
from street food, utility bills and template for transport systems across China.

\section{Survey Results}

An online survey conducted to measure the rider's perspective on using account-based ticketing versus the conventional closed loop scheme. The study is conducted on Dubai commuters and consisted of the following (Figures 1-5).

Nol Card is the propitiatory scheme used for Dubai transportation-similar to Oyster card in the UK.

The survey of 18 commuters (combination of female and male commuters, ages 20 to 50) across the emirate of Dubai, I've asked commuters 8 questions on their perspective on using account-based ticketing versus the conventional closed loop scheme. This section provides a summary and overview of the key analytical points of the poll. As I found in the focus group phase of this research, a private car is the most widely used mode of transportation for commuters. Commuters across the nation are unwilling to give up their personal vehicles in favor of public transport irrespective of the enormous investment in the sector. However, $31 \%$ of them have used their vehicles on a regular basis. Given with several modes of payment, the majority of the surveyee claimed that they pay over-the-counter payment method when paying their transportation. When asked which options would be their most preferred method of payment when given a choice, $76 \%$ answered they prefer using their debit or credit card.

\section{Conclusions}

One of the main advantages for operators using account-based ticketing is the cost reduction from running a proprietary card and offsetting the cost of cash management. With a rich fare policy that can be linked to data, operators have

\section{Methods of transportation (check all applicable)}

Answered: 18 Skipped: 0

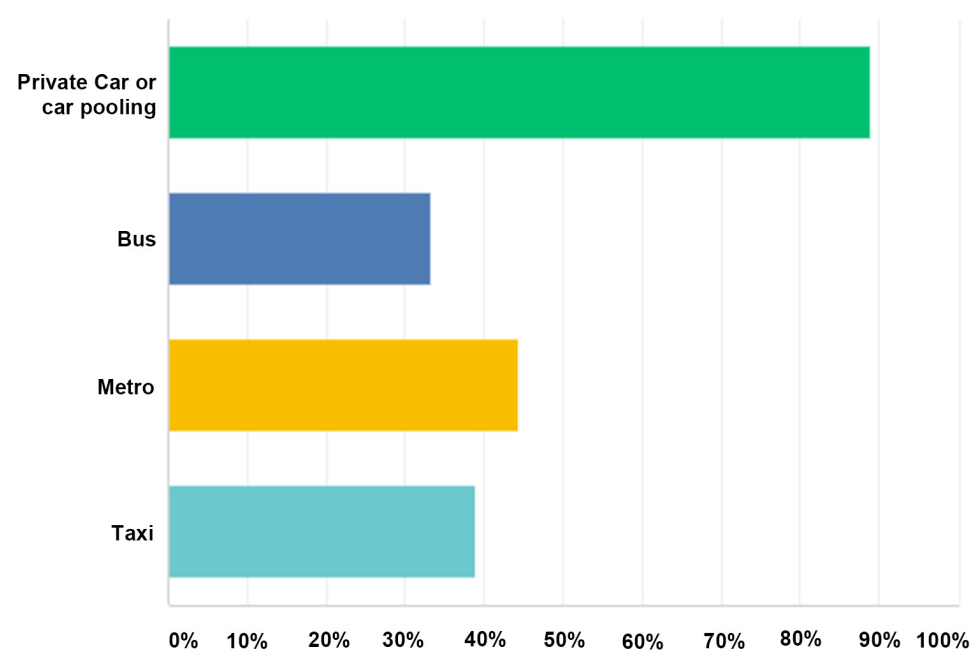

Figure: 1. Methods of transportation used [12]. 
How frequent you use public transportation

Answered: 18 Skipped: o

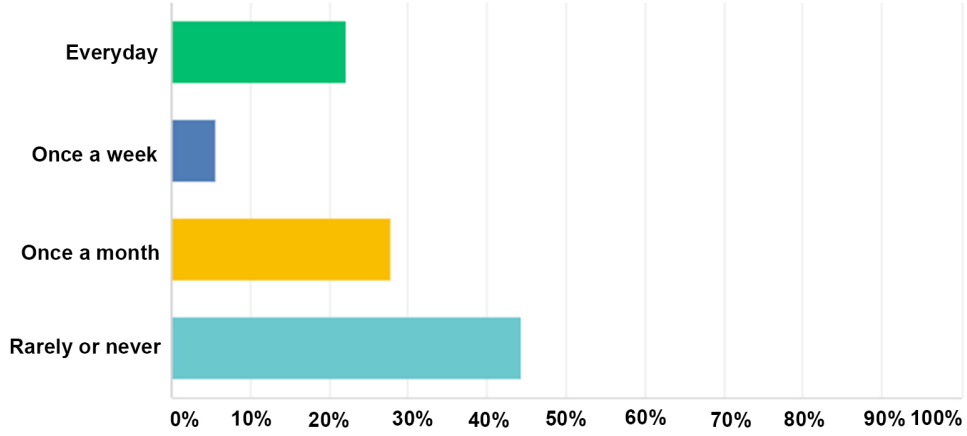

Figure 2. Frequency of using public transportation [12].

How do you normally pay for your journey (check all applicable)

Answered: 17 Skipped: 1

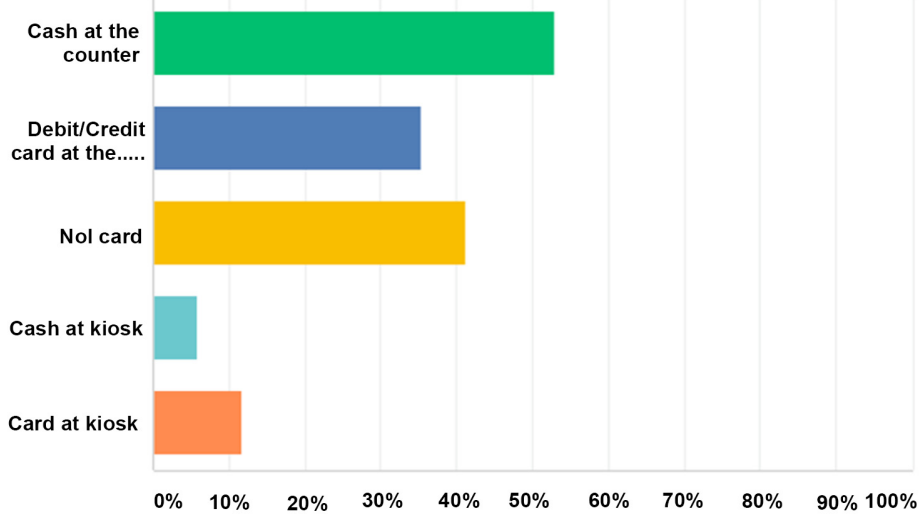

Figure 3. Payment methods used in daily commute [12].

Which of the options would be your most preferred method of payment if given the choice (choose only one)

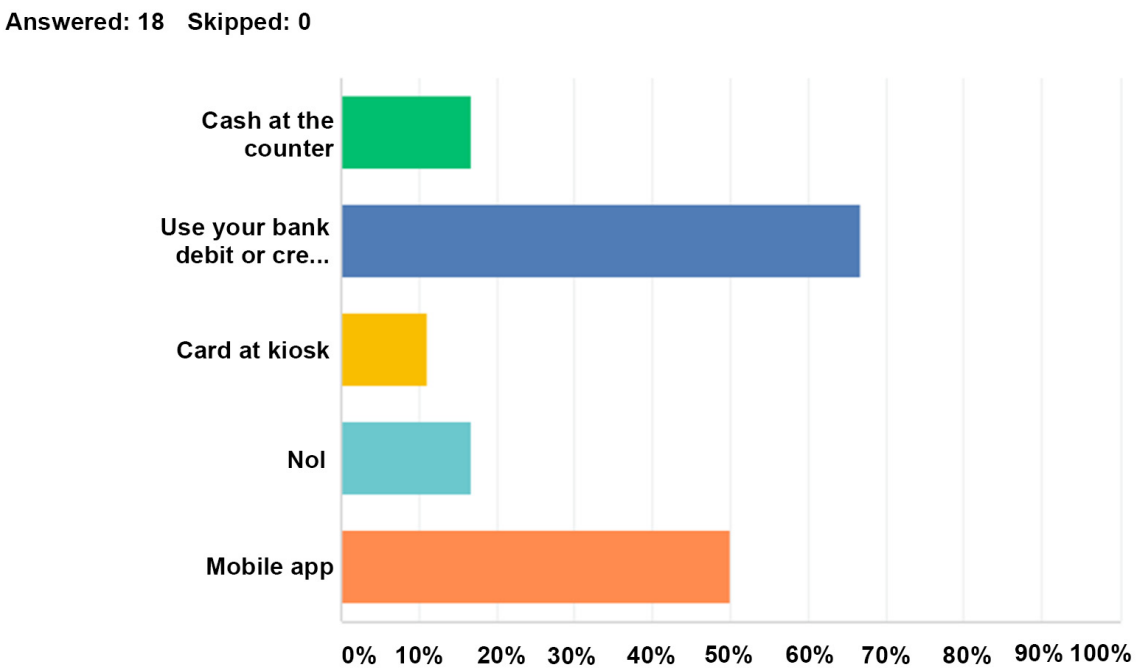

Figure 4. Preference of payment methods used in transportation [12]. 


\section{Do you use Nol card for purchaing}

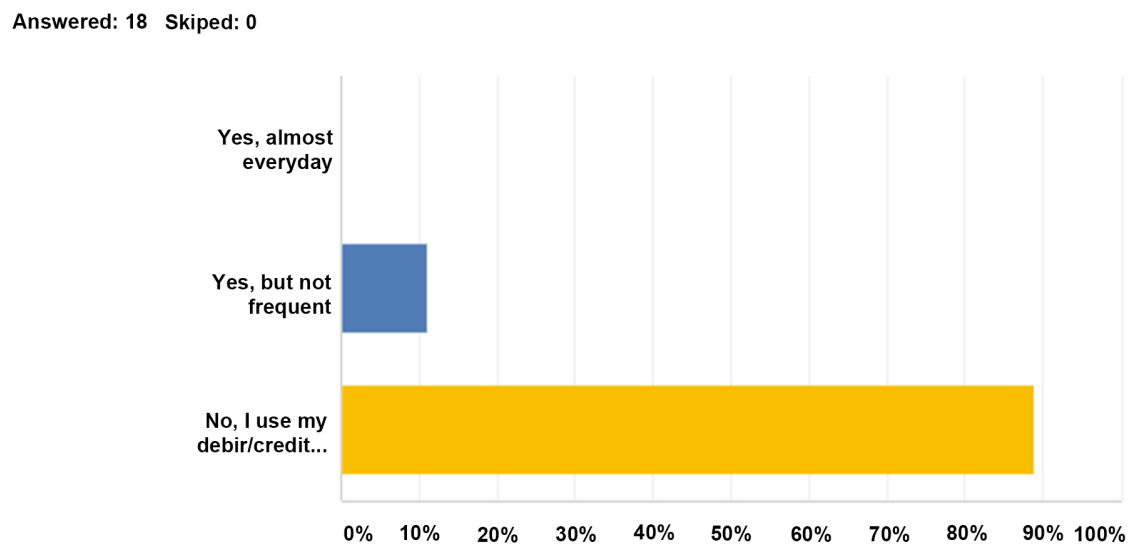

Figure 5. Using the transport card for retail purchase [12].

higher chances to engage with the customer and develop a targeted loyalty and rewards program whilst generating commercial benefits. The other advantages are summarized hereafter:

\section{- Leaner and streamlined operations}

Using the standard payment instruments enable flexible business models. It facilitates the variable pricing models to encourage more usage, and reduce the cost of ticket issuance and support. Finance operations will be easier and more manageable with the direct collection by acquirers.

\section{- Loss of card doesn't mean the loss of funds}

Since the account balance and card information are not stored on the card, if the traveler loses the card then he just follows the standard process with his card issuer and doesn't need to contact the transit authorities.

\section{- Customer convenience and choice}

Account based ticketing is an enabler of mobile and contactless which would give more choices to the customer. As the tickets are managed in back-office, riders can choose from a broader range of payment options to identify themselves whether being a smartcard, mobile device, wearable or future technology. Additionally, travelers who opted for prefunded-ABT account no longer concerned about the balance for their next journey.

To sum up, as a transit fare collection system transforms with advances in payment technology, there are different avenues for future research in this aspect. Further equity studies might help transit institutions understand possible availability concerns for transit riders. Equity analyses must be performed in other metropolitan areas as well to fully understand general trends which may influence the introduction of open payment systems. Finally, as mobile payment alternatives become more conventional in the transit system, the contrast of the adoption of bankcards along with mobile devices is another valued area for further research. 


\section{Conflicts of Interest}

The author declares no conflicts of interest regarding the publication of this paper.

\section{References}

[1] (2017) Global Mobility Report. https://openknowledge.worldbank.org/bitstream/handle/10986/28542/120500.pdf

[2] ACI-World Mass Transit Survey. https://www.aciworldwide.com/-/media/files/collateral/trends/2016-aci-worldwidemass-transit-payments-survey-tl-us.pdf

[3] Boston Federal Reserve Report. https://www.bostonfed.org/-/media/Documents/economic/cprc/publications/briefi $\underline{\text { ngs/transit.pdf }}$

[4] (2010) First Data-Transit Payment Systems. https://www.firstdata.com/downloads/thought-leadership/transit-payment-systems =wp.pdf

[5] (2017) World Payment Report, Capgimini. https://www.capgemini.com/fr-fr/wp-content/uploads/sites/2/2017/10/world-paym ents-report-2017_year-end_final_web-002.pdf

[6] (2017) First Data Report.

https://investor.firstdata.com/quarterly-financials/2017

[7] Department of Transport-London, TfL Transit Report. https://assets.publishing.service.gov.uk/government/uploads/system/uploads/attach ment_data/file/661933/tsgb-2017-report-summaries.pdf

[8] (2009) CUBIC.

http://www.annualreports.com/HostedData/AnnualReportArchive/c/NYSE_CUB_2 012.pdf

[9] Singapore Land Transport Authority Report. https://www.lta.gov.sg/content/dam/ltaweb/corp/PublicationsResearch/files/Annual Reports/1617/LTA\%20ANNUAL\%20REPORT\%202016-2017.pdf

[10] Queensland's Public Transport. https://translink.com.au/about-translink/reports-and-publications

[11] Yikatong News. http://www.ecns.cn/cns-wire/2017/08-14/269255.shtml

[12] Customer Field Survey, Survey Monkey. https://www.surveymonkey.com/r/YQ689SP 